\title{
Desarrollo de dos protocolos de micropropagación in vitro de las musáceas guineo manzano (musa $A A$ ) y dátil (musa $A A B$ ), de valor comercial y nostálgico para El Salvador, para su posterior incorporación en dos parcelas productivas
}

María Elena Montes de Godoy

Máster en Hortofruticultura, Universidad de Talca, Chile

Docente-Investigadora, Facultad de Ingeniería y Arquitectura

Universidad Católica de El Salvador

Email: maria.montes@catolica.edu.sv

\section{RESUMEN}

Recepción: 2012-02-16

Aceptación: 2012-04-18

Este estudio se basa en la importancia que tienen las musáceas de guineo dátil $(A A)$ y manzano $(A A B)$ en la dieta salvadoreña, así como su relevancia económica, social y nostálgica para el país. El propósito del experimento fue desarrollar un protocolo eficiente para reproducir estas especies en laboratorio, para luego entregarlas a pequeños productores agrícolas de dos cooperativas nacionales. El proceso se compuso de cinco diferentes fases: establecimiento, multiplicación, desarrollo, enraizamiento y aclimatación de las especies. El ensayo se realizó bajo condiciones controladas dentro de un laboratorio, en donde se obtuvieron los hijos de espada que sirvieron como fuente de semilla. Los cormos se redujeron y lavaron con Tween 80. Cada muestra se desinfectó con lejía pura (hipoclorito de sodio al 5.25\%). Los meristemas extraídos de los cormos fueron colocados en un medio de cultivo nutritivo MS (Murashige \& Skoog, 1962), conteniendo $5.0 \mathrm{mg} / \mathrm{l}$ de la citoquinina BAP (Bencilaminopurina) y un $\mathrm{pH}$ de 5.8. En ambos casos la respuesta de las muestras fue similar con respecto las condiciones in vitro.

En un inicio el guineo manzano respondió mejor a la multiplicación, pero la oxidación limitó en gran medida la obtención de una mayor cantidad de explantes de esta variedad. Este fenómeno se controló con la aplicación de $125 \mathrm{mg} / \mathrm{l}$ de ácido ascórbico al cultivo. Al final de los diez ciclos de multiplicación se obtuvieron 2,500 plantas de cada especie. Éstas fueron enraizadas, aclimatadas y entregadas a dos cooperativas de pequeños productores nacionales. 
[ 34 ] Universidad Católica de El Salvador.

Palabras claves: micropropagación, musáceas nostálgicas, medio Murashige \& Skoog, Bencilaminopurina.

\section{ABSTRACT}

This research is based on the importance of the Musaceae datil banana (AA) and apple banana $(\mathrm{AAB})$ in the Salvadoran diet; as well as the economic and social importance of this fruit to the country. The purpose of the research was to develop an efficient protocol to reproduce this species in a lab and then deliver them to small farmers from two co-ops. The process was composed of five phases: establishment, multiplication, development, rooting and acclimatization of species. The experiment was carried out under controlled conditions in the lab, in which sword field sprouts were used as seed source. The corms were cut and washed with Tween 80; each sample was disinfected with pure bleach (sodium hypochlorite 5.25\%).The corms extracted from meristems were placed in a nutrient culture medium MS (Murashige \& Skoog, 1962), containing $5.0 \mathrm{mg} / \mathrm{l}$ of cytokinin BAP (benzylaminopurine) and a pH of 5.8. In both cases, the response of the samples was the same as in vitro conditions.

At the beginning, the apple banana responded better to the multiplication; the oxidation largely limited to obtain a greater number of explants of this variety. This phenomenon was controlled applying125 mg/l of ascorbic acid to the culture. At the end of the ten multiplication cycles, 2,500 plants were obtained from each species, which were rooted, acclimatized to be given to small farmers from two co-ops

Key words: micropropagation, nostalgic musaceae, Murashige \& Skoog means, Benzylaminopurine

\section{INTRODUCCIÓN}

En El Salvador existen problemas de abastecimiento con respecto a las musáceas dentro del mercado nacional, a pesar que el cultivo de éstas representa un rubro importante en términos económicos y nutricionales para el país. Esto obliga a que se eroguen recursos estatales para importar este tipo de productos desde Guatemala y Honduras para suplir la demanda nacional. 
Los volúmenes de musáceas producidos por nuestro país alcanzan las 75,709 toneladas por año, lo que equivale a una superficie cultivada de 2,427 hectáreas. Esto representa un volumen de importación de 52,650 toneladas, que serían completamente factibles de producir en el territorio nacional, siempre y cuando se brindaran las respectivas facilidades técnicas y económicas (CENTA, 1994).

En el país existen varias musáceas criollas que son muy apetecidas por la población y que, actualmente, son consideradas nostálgicas por su escasez. Entre estas especies se pueden mencionar el guineo manzano y dátil, majonchos, plátanos, etc. Sin embargo, en el país ya no se cuenta con plantaciones comerciales que produzcan estas especies, debido a la poca disponibilidad de material para iniciar sembradíos y la falta de uniformidad en los productos.

Con respecto a la disponibilidad de material de musáceas en general, el cultivo requiere de grandes cantidades de semilla, ya que para cultivar una hectárea se necesitan 1,110 plantas (siembra en cuadro) y 1,470 (siembra en triángulo) (Rodríguez et al., 2002). Esto constituye una fuerte limitante para la obtención de semilla en la cantidad requerida, además de un alto riesgo de contaminación con enfermedades y plagas, altos costos de transporte y las respectivas restricciones aduaneras, en el caso de importar el insumo.
Una de las soluciones para satisfacer las necesidades de abastecimiento y, por ende, mejorar la alimentación, es la implementación de técnicas para el mejoramiento genético, sanitario y la multiplicación masiva de musáceas, con características deseables en un corto plazo de tiempo. Esta iniciativa es posible mediante la técnica de cultivo de tejidos vegetales (FHIA, 1994; INIBAP, 2004)

\section{MATERIALES Y MÉTODOS}

\subsection{Introducción del material}

Se trabajó con musáceas de dos especies: guineo dátil ( $\mathrm{AA})$ y manzano ( $\mathrm{AAB})$, mediante la vía de regeneración de organogénesis directa a partir de la yema central del cormo. Se utilizaron 27 yemas de dátil y 22 yemas de manzano (Figura 1a).

Las yemas se lavaron con Tween 80 , a razón de 3 gotas $/ 100 \mathrm{ml}$ de agua de chorro. Posteriormente, éstas se redujeron con el cuchillo hasta más o menos $1 \mathrm{~cm}$ de diámetro y $4 \mathrm{~cm}$. de altura (Figura 1b). Luego se sumergieron en solución de hipoclorito de sodio al 5.25\% (lejía comercial). Se mantuvieron en cámara durante 15 minutos y después se enjuagaron tres veces con agua desmineralizada estéril (Figura 1c). Posteriormente se hizo una disección longitudinal y transversal con un 
bisturí hasta obtener el meristema apical de aproximadamente $3 \mathrm{~mm}$ de radio y $5 \mathrm{~mm}$ de altura (Figura 1d). Inmediatamente se procedió a inocular en medio MS (Murashige \& Skoog, 1962) con $5 \mathrm{mg} / \mathrm{l}$ de la citoquinina BAP y pH de 5.8.

El fotoperíodo fue de 16 horas luz y 8 horas de oscuridad con 1350 Lux de intensidad, a temperaturas entre $25-30^{\circ} \mathrm{C}$.

\subsection{Establecimiento}

Luego de 40 días, las yemas fueron transferidas a la fase de establecimiento. En este caso no se realizó ningún corte a los explantes. Para esta etapa también se utilizó medio de cultivo MS más BAP, a razón de $5.0 \mathrm{mg} / 1$.

El fotoperíodo también fue de 16 horas luz y 8 horas de oscuridad con 1350 Lux de intensidad, con temperaturas entre $25-30^{\circ} \mathrm{C}$.

Figura 1. Proceso de introducción de cormos de las musáceas guineo dátil y manzano a las condiciones del laboratorio de la UNICAES en el mes de Octubre de 2008, a) Proceso de reducción de cormos en el laboratorio b) Yemas extraídas, seccionadas y limpias c) Proceso de desinfección en cámara de flujo laminar d) Inoculación de meristema apical en su respectivo medio de cultivo.

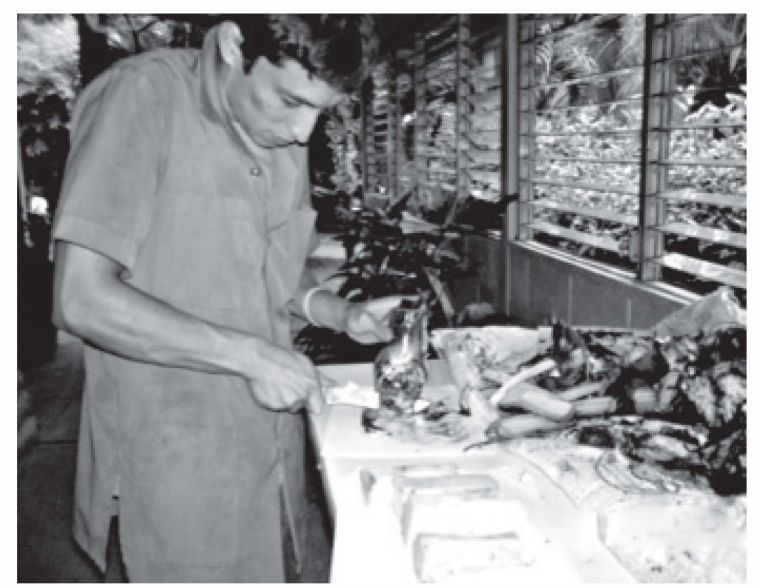

a)

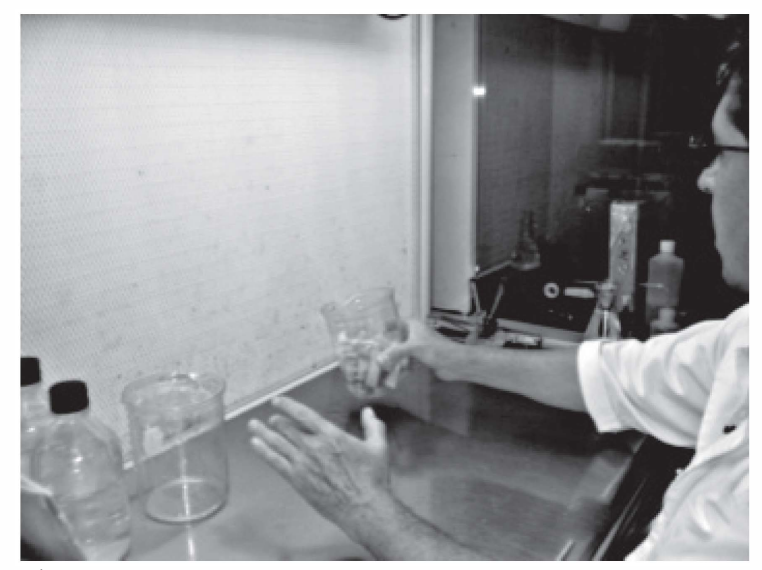

c)

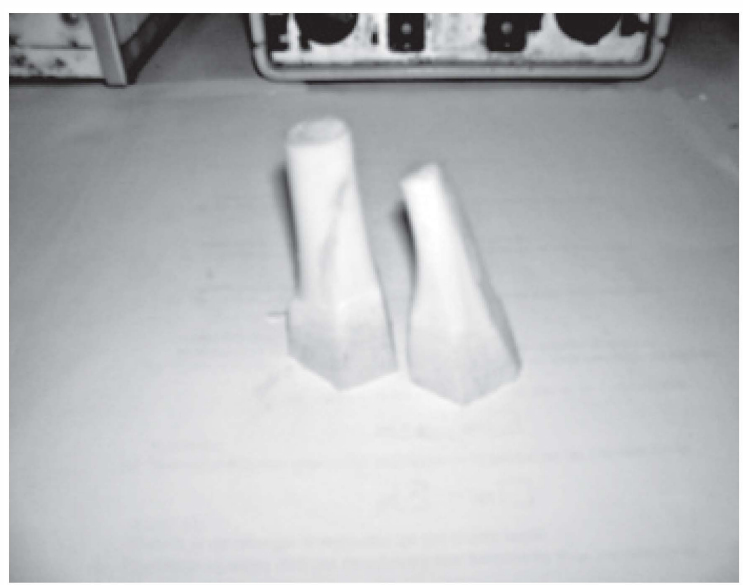

b)

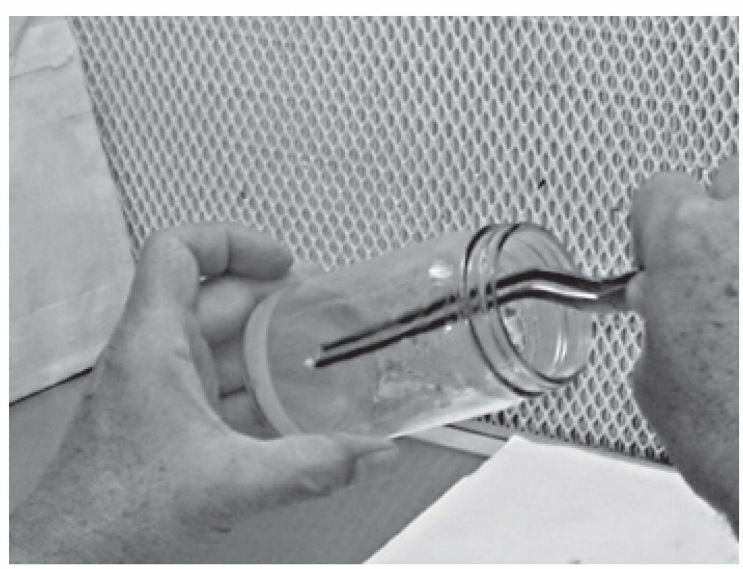

d)

Volumen No. 1 Desarrollo de Protocolo de Micropropagación In Vitro 


\subsection{Multiplicación (Primer ciclo)}

Aquí también se utilizó el medio de cultivo MS con $5 \mathrm{mg} / \mathrm{l}$ de BAP. Sin embargo, las yemas se limpiaron cuidadosamente con bisturí para eliminar la oxidación preliminar. Los brotes de guineo dátil se observaron un poco menos desarrollados que los de manzano, a pesar que las condiciones de incubación fueron las mismas para ambas especies durante todas las fases del cultivo.

\subsection{Segundo ciclo}

Se empleó el medio de cultivo MS con 0.5 mg/l de carbón activado, debido a la presencia de oxidación en la asociación entre el medio y el explante. Además se hicieron los siguientes tratamientos: 0.0, 2.0, 4.0 y $6.0 \mathrm{mg} / \mathrm{l}$ de BAP en bloques al azar, para poder establecer una comparación posterior y determinar la dosis más apropiada en cada cultivo. Esto comprobó que los retoños de guineo dátil estaban más desarrollados que los de manzano. La transferencia en cámara se realizó limpiando las zonas necróticas de cada yema, para luego cortar en dos partes y después colocar los explantes con el ápice invertido en el medio de cultivo.

\subsection{Tercer ciclo}

El medio de cultivo MS se mantuvo, pero con una dosis de $6.0 \mathrm{mg} / \mathrm{l}$ de BAP, (ésta resultó más eficiente para incrementar la producción de yemas, en aproximadamente un promedio de 3.5 explantes), con $0.5 \mathrm{mg} / \mathrm{l}$ de carbón activado. (Éste, al igual que en los casos anteriores, se utilizó para evitar la oxidación).

\subsection{Cuarto ciclo}

En esta fase se utilizó medio líquido de la solución, inyectado directamente a los frascos de ambas especies, debido a la carencia de material. El medio consistió en sales y vitaminas MS con $6.0 \mathrm{mg} / \mathrm{l}$ de BAP.

\subsection{Quinto ciclo y subsiguientes (sex- to, séptimo y octavo)}

Para esta etapa se volvió a utilizar un medio semisólido MS sin carbón activado. Se analizó la posibilidad de que éste último recurso estuviera interfiriendo con la adecuada absorción de las citoquininas del medio nutritivo. Es decir, que éste estuviera absorbiendo las sustancias que hacen multiplicar los brotes, aún cuando el reactivo fue aplicado para contrarrestar el problema grave de oxidación. $\mathrm{Al}$ medio de cultivo utilizado siempre se le adicionó $6.0 \mathrm{mg} / \mathrm{l}$ de BAP. En los subsiguientes ciclos se empleó glucosa como fuente inmediata de carbohidratos, así como también se incrementó la dosis de citoquinina BAP hasta $8.0 \mathrm{mg} / \mathrm{l}$, en espera de un incremento en la tasa de multiplicación. 
Se utilizó el ácido cítrico como alternativa respecto al carbón activado, para ver su control sobre la oxidación. Las dosis empleadas fueron de $0.25 \mathrm{mg} / \mathrm{l}$ y de $0.5 \mathrm{~g} / \mathrm{l}$., para cada elemento respectivamente. Los efectos del ácido cítrico parecían funcionar, pero su resultado fue similar a los del carbón activado. Aún cuando este último elemento mejoró la oxidación, debido a su retención de citoquinina, las plántulas ya formadas presentaron formación de raíces. En conclusión, con ninguno de los dos tratamientos se pudo controlar la dominancia apical de las puntas de los brotes. Esto originó pérdida del vigor para seguir multiplicándose. Posteriormente estas dos sustancias se sustituyeron por ácido ascórbico.

\subsection{Noveno ciclo}

Para la etapa de corte de insumos de musáceas ya se había superado la oxidación y se había eliminado la dominancia apical, que evitaba que el material multiplicara brotes laterales. También se había eliminado la excesiva producción de raíces, que presentaban los explantes sometidos a carbón activado. La alternativa del uso del ácido cítrico resultó también buena para el control de la oxidación, sin promover la formación de raíces, como lo hacía el otro componente. No obstante se disminuyó la concentración de 0.25 g/l a 0.125 $\mathrm{mg} / \mathrm{l}$, debido a que las plántulas se encontraban necrosadas en las puntas de las hojas.
En este período se ensayó simultáneamente someter a los explantes a medio líquido, utilizando siempre medio MS, pero con macrosales reducidas en un $20 \%$, el azúcar a razón de $20 \mathrm{~g} / \mathrm{l}$, en vez de $30 \mathrm{~g} / \mathrm{l}$; así como la citoquinina mantenida siempre a $6.0 \mathrm{mg} / \mathrm{l}$ y sin antioxidantes. Por cada Erlenmeyer de $225 \mathrm{ml}$ se pusieron $50 \mathrm{ml}$ de medio de cultivo, con tres explantes en cada uno. Por otra parte, hubo un fallo en el manómetro de autoclave o esterilizador, lo cual hizo que parte del medio de cultivo elaborado se contaminara, siendo esto visible hasta dos o más días después de elaborado el medio. El problema se produjo sólo en el medio de guineo manzano. Salvo de percance, se pudo observar mayor número de masivos, en un $15 \%$ de la población total, lo cual se esperaba se incrementara de manera general en todos los frascos.

Para un nuevo cambio de medio de cultivo se utilizaron medios semisólidos, MS completo, con $125 \mathrm{mg} / \mathrm{l}$ de ácido cítrico, menos de la cantidad anterior, los brotes se encontraban necrosados en las puntas de las hojas. Además se decidió emplear Phytagel en vez de Agar, para solidificar medios de cultivo, en función de aprovechar el efecto visual que produce su transparencia y que permite detectar la contaminación bacteriana y/o fúngica. El medio líquido ya no se empleó, por cada yema se obtuvo una tasa promedio de 1:1. Los explantes también se decapitaron nuevamente para estimular el brote lateral. 


\subsection{Décimo ciclo (Enero 2010)}

Para el corte de enero, las cantidades de material de ambas especies se incrementaron notablemente (1975 yemas para dátil y 1500 para manzano), alcanzando tasas de multiplicación de 2.4 para el caso de guineo dátil y de 1.6 para el guineo manzano. Por tanto, según la proyección, se esperaba tener completo y superado el número de plantas pronosticadas para mediados de febrero (aproximadamente 2500).

Para ese tiempo, el guineo manzano ya se encontraba en desarrollo en medio de cultivo MS completo con $1 \mathrm{mg}$ de BAP.

Por otra parte, el guineo dátil se encontraba en su última fase de multiplicación, colocándose también en un medio de cultivo MS con $6.0 \mathrm{mg} / \mathrm{l} \mathrm{de}$ BAP, pero con $125 \mathrm{mg} / \mathrm{l}$ de ácido ascórbico.

\subsection{Fase de desarrollo}

Durante esta etapa ya se contaba con el número de plantas esperado (2500 plantas de cada especie), solamente se encontraban desarrollando y diferenciando los últimos brotes hasta terminar de adquirir la estructura de plantas completas. El 12 de febrero se le agregó a toda la población de frascos de ambas especies medio de cultivo MS líquido, con 1 mg de BAP para que los brotes siguieran creciendo. Era la segunda vez que se agregaba al guineo manzano y la primera en dátil.

Se estimó que entre la última semana de marzo y la primera de abril, las plantas de ambas especies ya estarían listas para salir a aclimatación, fase que se esperaba durara de entre 15 y 20 días, dependiendo del comportamiento de las plántulas recién transferidas a bandejas con sustrato de Peat moss (mezcla comercial de musgo mineral).

\subsection{Fase de enraizamiento}

Una vez obtenido el número de plantas esperado para cada especie (2500 plantas) desarrolladas y diferenciadas, se realizaron tres inyecciones de medio de cultivo MS con $1 \mathrm{mg}$ de BAP/l a cada frasco, para que los brotes pequeños terminaran de crecer y las plantas tuvieran reservas nutritivas suficientes. La cantidad aplicada a cada frasco fue de aproximadamente 10 a $15 \mathrm{ml}$. Este procedimiento se realizó dos veces en dátil y en manzano. La última vez se realizó solo a manzano, agregando siempre medio MS, pero sin hormonas.

María Elena Montes de Godoy Volumen No. 1 


\subsection{Proceso de aclimatación}

En esta etapa las plantas salen de la fase in vitro y pasan a vivir como plantas autótrofas, para lo cual son transferidas a bandejas de germinación con un sustrato estéril. Este sustrato puede ser piedra pómez, vermiculita, turba, etc.; siempre y cuando se mantenga una alta humedad relativa (arriba de 95\%), debido a que estas plantas tienen la cutícula (capa de cera) escasamente desarrollada (Alvarenga, 2007). Esto se consigue tapando las bandejas con un plástico transparente y retirándolo poco a poco entre 6 y 10 días después de la transferencia.

Para el estudio, desde la primera semana de mayo se comenzó el proceso de aclimatación con el guineo dátil. En promedio, por frasco destapado se tenían 20 plantas. El proceso consistió en el lavado de las raíces con agua de chorro, cortando al mismo tiempo las raíces y la mitad de la base foliar, para evitar la pérdida de agua que se produce al pasar de un medio de alta humedad relativa (90-100\%) a uno de humedad ambiental más baja (6585\%) (Figura 2a y 2b)). Luego se introdujeron en una solución anti fúngica con Previcur, a razón de $1 \mathrm{ml} / \mathrm{l}$ de agua durante media hora. Posteriormente, las plántulas se introdujeron en bandejas con un sustrato comercial de primera calidad, denominado Peat moss (mezcla comercial de musgo mineral canadiense con turba).
Las bandejas completas se llevaron al vivero del laboratorio, en donde se había preparado una especie de incubadora cubierta de plástico transparente para las plántulas, brindando riegos atomizados de dos a tres veces al día. Se colocó también un termómetro de temperatura máxima y mínima, registrando temperaturas entre 22 y $28^{\circ} \mathrm{C}$.

La preparación de sustrato de las bolsas consistió de un 70\% de tierra negra (de cafetal); un $30 \%$ de cascajo fino (piedra pómez) y un $10 \%$ de granza de arroz. La desinfectación de la mezcla se realizó con Bayfidán triple, a razón de $4 \mathrm{~g}$ por bolsa.

\subsection{Transferencia a bolsa}

Esta etapa se realizó transfiriendo las plántulas listas y endurecidas de su fase de aclimatación, directamente a la bolsa con la mezcla preparada anteriormente. $\mathrm{Al}$ momento de la siembra se aplicó $1.5 \mathrm{cc} / \mathrm{l}$ de insecticida Monarca y $1.5 \mathrm{cc} / \mathrm{l}$ de Previcur (fungicida). Ocho días después de la siembra se aplicaron 2 g/ planta de fertilizante completo Blaukorn (Figura 2c).

Debido a que los meses de julio y agosto fueron demasiado lluviosos, hubo pérdidas de plantas por la alta incidencia de hongos. Se estima que el porcentaje de pérdida fue del 
$20 \%$. No obstante, el material se fue sustituyendo con plantas de las reservas. El tratamiento empleado para erradicar el problema de las plantas se realizó con el fungicida de amplio espectro denominado Amistar (Syngenta), a razón de $10 \mathrm{~g} /$ bomba de 4 galones.

Figura 2. Panorámica general del proceso final de aclimatación de plántulas de las condiciones in vitro a ex vitro en el vivero de UNICAES, así como entrega a beneficiarios. a) Lavado de plántulas con agua de grifo b) Siembra de plántulas con sistema radicular y una parte del foliar cortado c) Plantas de guineo dátil y manzano con un mes de crecimiento en condiciones ex vitro d) Entrega a los beneficiarios en cantón Chilcuyo, Santa Ana.

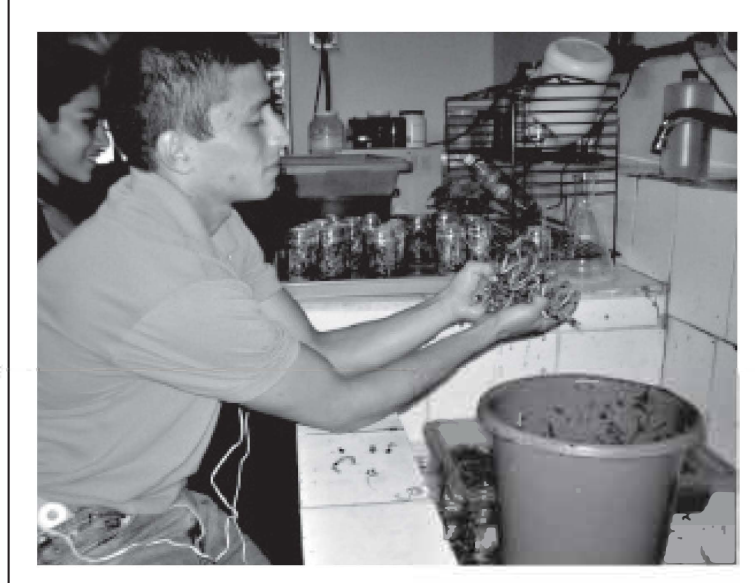

a)

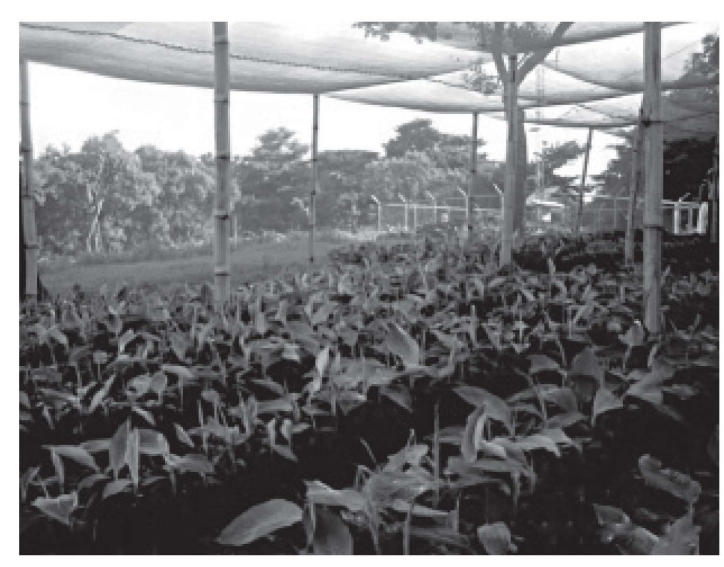

c)

\section{RESULTADOS Y DISCUSIÓN}

Después de dos meses de iniciada la siembra de ambas especies de musáceas, se observó la presencia de oxidación generalizada en los

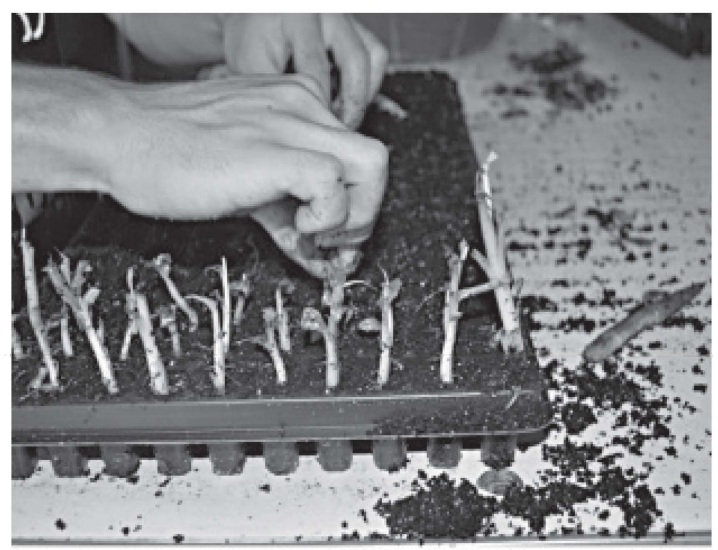

b)

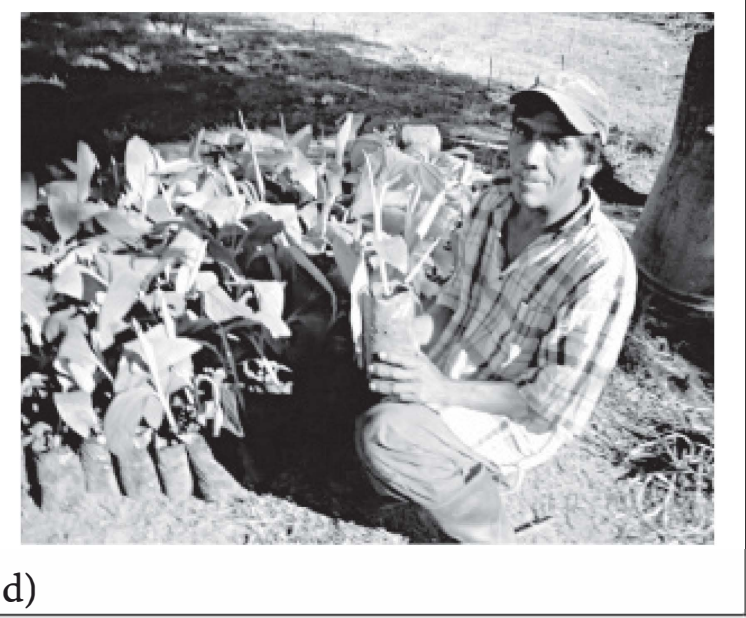

explantes. Esto dificultó el hinchamiento de las yemas para dar inicio al seccionamiento de las mismas e incrementar la cantidad de material disponible. Las yemas de guineo dátil se observaron menos desarrolladas que las de 
manzano. En el medio de cultivo inicial MS, (Murashige \& Skoog, 1962), se adicionaron 5 $\mathrm{mg} / \mathrm{l}$ de la citoquinina BAP (Bencilaminopurina), debido a que fue la dosis que mejores resultados presentó en las condiciones del laboratorio de la Universidad Católica de El Salvador, UNICAES, para la multiplicación de las musáceas estudiadas: plátano enano y guineo de seda.

Posteriormente se probaron otras dosis de reguladores de crecimiento, siendo 0.0, 2.0, 4.0 y $6.0 \mathrm{mg} / \mathrm{l}$ de BAP para establecer una dosis apropiada para multiplicar el material. No obstante, resultó ser mejor la dosis de 6.0 $\mathrm{mg} / \mathrm{l}$ para ambos cultivos, por lo que se optó aplicarla en los subsiguientes ciclos de multiplicación. Además se aplicó un absorbente carbonáceo a razón de 0.5 g/l para contrarrestar el problema de oxidación (AROMATECA, 2002; Díaz et al., 2006). Conforme pasaron estos ciclos se observó que el número de yemas multiplicadas seguía en tasas promedio de 1.1 para guineo dátil y de 1.2 para guineo manzano, lo que se mantuvo por aproximadamente cuatro meses. Luego se determinó que, el reactivo aplicado para contrarrestar el problema grave de oxidación podría estar causando la retención de la citoquinina aplicada al medio de cultivo para favorecer la multiplicación. Este problema es posible según lo expresado por Pierik (1990). Fue así como se aplicó al medio de cultivo glucosa, en vez de sacarosa como fuente inmediata de carbohidratos y se subió el BAP a $8.0 \mathrm{mg} / \mathrm{l}$. Sin embargo, esto no fue efectivo.

A sugerencia de Marroquín, (2009), se utilizó la alternativa del ácido cítrico en una parte del ensayo para comparar su efecto con el carbón activado en el control de la oxidación. Las dosis empleadas de ácido cítrico fueron de $0.25 \mathrm{mg} / \mathrm{l}$ y $0.5 \mathrm{~g} / \mathrm{l}$, respectivamente. Posteriormente se cambió a ácido ascórbico. Los efectos de esta mezcla parecían dar buen resultado, pero fueron similares a los del absorbente carbónico. La diferencia estuvo en que, si bien el ácido cítrico disminuyó la oxidación y no retuvo la citoquinina BAP, no favoreció la multiplicación de los explantes. Por su parte, el carbón activado mejoró la oxidación, pero debido a que siguió reteniendo la citoquinina, las plántulas ya formadas presentaron formación de raíces. Este fenómeno ocurre naturalmente cuando las citoquininas son suprimidas del medio. No obstante, esto no ofrece mayor inconveniente en la multiplicación del material, pues con cada decapitación de brotes éstas se eliminan aunque sigan germinando. En nuestro caso, con ninguno de los dos tratamientos en ambas especies se pudo controlar la dominancia apical de las puntas de los brotes y, por lo tanto, se perdió el vigor para seguir multiplicando.

La alternativa del uso del ácido ascórbico resultó también buena para el control de la oxi- 
dación sin promover la formación de raíces, como en el caso de carbón activado. No obstante se disminuyó la concentración de 0.25 g/l a $0.125 \mathrm{mg} / \mathrm{l}$, debido a que las plántulas se encontraban necrosadas en las puntas de las hojas.

Posteriormente se utilizó medio de cultivo líquido, tal como lo recomendó Orellana (2009); utilizando siempre medio MS, pero macrosales reducidas en un $20 \%$, el azúcar a razón de 20 g/l, en vez de 30; así como la citoquinina mantenida siempre a $6.0 \mathrm{mg} / \mathrm{l}$. No obstante, al eliminar los antioxidantes de esta manera, igual se comprobó que los medios de cultivo sin antioxidantes eran perjudiciales para ambas especies de musáceas.

Si bien hasta ese momento ya se consideraba controlada toda la oxidación, el número de explantes o brotes se mantuvo más bajo respecto al mes anterior, (118 yemas para manzano y 121 para dátil), debido a que hubo un fallo en el manómetro de autoclave o esterilizador, lo cual hizo que parte del medio de cultivo elaborado se contaminara. Esto fue visible hasta dos o más días después de elaborado. El problema fue sólo en el medio de guineo manzano. Aparte de esto, se observó la formación de mayor número de masivos, en un $15 \%$ de la población total, lo cual se esperaba se incrementara de manera general en todos los frascos.
Para un nuevo cambio de medio de cultivo se utilizaron medios semisólidos, MS completo, con $125 \mathrm{mg} / \mathrm{l}$ de ácido ascórbico, menos de la cantidad anterior, puesto que los brotes se encontraban necrosados en las puntas de las hojas. Además se había decidido emplear Phytagel en vez de Agar, para solidificar medios de cultivo, debido a la transparencia que produce, permitiendo un mejor efecto visual de la contaminación bacteriana y/o fúngica. El medio líquido ya no se empleó, pues por cada yema se obtuvo una tasa promedio de 1:1. Los explantes también se decapitaron nuevamente para estimular el brote lateral.

Luego de esta situación, la tasa de multiplicación se incrementó de forma notoria, alcanzando tasas de multiplicación de 2.4 para el caso de guineo dátil y de 1.6 para el guineo manzano, con lo que se consiguió el número de plantas esperado (Figura 3 ).

Posteriormente, en la fase de desarrollo, se utilizó siempre MS completo, bajando la dosis de BAP a $1 \mathrm{mg} / \mathrm{l}$ para ambas especies. Al disminuir el BAP de 6.0 a $1.0 \mathrm{mg} / \mathrm{l}$ se logró que la planta se desarrollara y, a la vez, se multiplicara un poco más por el efecto residual que deja la misma citoquinina en el tejido vegetal.

Debido a que el material de ambas especies se comportó similar en todas las fases del ensa- 
[ 44 ] Universidad Católica de El Salvador.

Figura 3. Comportamiento de las tasas de multiplicación de guineo dátil y manzano de junio de 2009 a enero de 2010, fechas en las que se alcanzó a producir el número de plantas deseadas de cada especie.

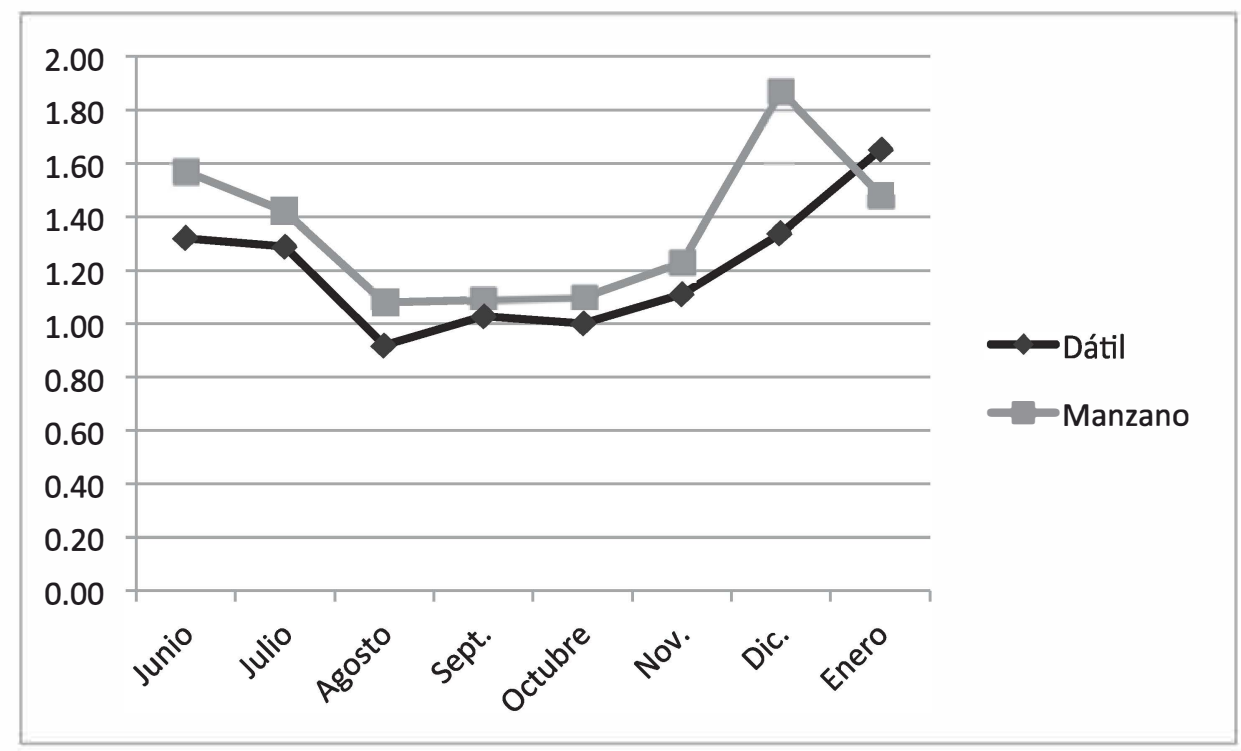

yo, se determinó presentar un solo protocolo de micropropagación aplicable para las dos.

\section{CONCLUSIONES}

A pesar que las dos especies de musáceas estudiadas (guineo dátil AA y manzano $\mathrm{AAB}$ ) tienen un alto valor nostálgico para El Salvador, este estudio es pionero en cuanto a su reproducción in vitro y; por tanto, un precedente para el establecimiento de un protocolo para su propagación comercial.

Es importante que antes de iniciar una introducción in vitro de musáceas de las que no existe algún antecedente de micropropagación, los explantes se inoculen previamente en soluciones antioxidantes para evitar problemas en la multiplicación del material. Se recomienda esto debido a que la oxidación de polifenoles es una de las dificultades prácticas más importantes en la propagación in vitro de las musáceas (Angarita y Perea, 1991).

La utilización del carbón activado para contrarrestar la oxidación durante mucho tiempo, -aproximadamente 6 meses-, fue perjudicial dentro del ensayo, debido a la retención de la citoquinina BAP. Este hecho dificultó alcanzar las cantidades de plantas necesarias para ambas especies.

Aunque al principio de la prueba el guineo manzano presentó mejor comportamiento 
con respecto al guineo dátil, en la recta final, las tasas de multiplicación fueron alcanzadas por éste último, lográndose el número de plantas necesarias de esta especie mucho más rápido.

\section{REFERENCIAS BIBLIOGRÁFICAS}

Alvarenga, S. (2007). Establecimiento in vitro y micropropagación de banano. (Manual de Laboratorio Cultivo de Tejidos I). Cartago: Instituto Tecnológico de Costa Rica (ITCR).

Angarita, A. y Perea, M. (1991). Micropropagación de plátanos y bananos. En Roca, W.M. y Mroginski, L.A. Cultivo de Tejidos en la Agricultura. Fundamentos y Aplicaciones. pp: 494-512. Cali. Centro Internacional de Agricultura Tropical (CIAT).

AROMATECA. (2002). Control de Pardeamiento Enzimático. En Fresh-cut fruits and vegetables Science Technology and Market. Recuperado de http://aromateca.com/main/index. php?option=com content\&task=view\&id=80\&Itemid $=5$.

Centro Nacional de Tecnología Agropecuaria y Forestal. (1994). Programa de Musáceas. San Andrés, La Libertad, El Salvador. División de Investigación.

Díaz, L.P; Namur J.J y Bollati, S.A. (2006). Efecto del ácido cítrico y del carbón activado en la regeneración de plantas de orquídeas (Laelia lundii) por cultivo in vitro de semillas. Buenos Aires. Recuperado de http://www.maa.gba.gov.ar/agricultura ganaderia/floricultura/.../25. doc.

Fundación Hondureña de Investigación Agrícola. (1994). Manual sobre micropropagación de banano y plátano. La Lima, Cortés, Honduras.

Marroquín, J.F. (2009). Comunicación personal. Director Nacional de Educación Superior. San Salvador: MINED (Ministerio de Educación). 
[ 46 ] Universidad Católica de El Salvador.

Orellana, M. (2009). Comunicación personal. Vice Decano de Facultad de Agronomía. San Salvador: UES (Universidad de El Salvador).

Murashige, T. \& Skoog, F. (1962). A revised medium for rapid growth and bioassays with tobacco tissue cultures. Physiol. Plant. 15: 473-497.

Pierik, R. L. M. 1990. Cultivo in vitro de las plantas superiores. Madrid: Editorial Mundi-Prensa. Red Internacional para el Mejoramiento del Banano y el Plátano. (2004). Usos y valor nutritivo del banano y plátano. Recuperado de www.inibap.org

Rodríguez C., M. y Guerrero, M. 2002. Cultivo de plátano. San Salvador: CENTA (Centro Nacional de Tecnología Agropecuaria y Forestal). 